\section{artelogie}

\section{Artelogie}

Recherche sur les arts, le patrimoine et la littérature de l'Amérique latine

2 | 2012

Mexique : espace urbain et résistances artistiques et littéraires face à la « ville générique »

\title{
La Siempre Viva Ciudad de México, antigua Tenochtitlán y futura Mexilópolis intergaláctica
}

\section{Marisa Lara y Arturo Guerrero}

\section{(2) OpenEdition \\ Journals}

Edición electrónica

URL: https://journals.openedition.org/artelogie/8122

DOI: $10.4000 /$ artelogie.8122

ISSN: 2115-6395

Editor

Association ESCAL

Referencia electrónica

Marisa Lara y Arturo Guerrero, «La Siempre Viva Ciudad de México, antigua Tenochtitlán y futura Mexilópolis intergaláctica», Artelogie [En línea], 2 | 2012, Publicado el 21 enero 2012, consultado el 07 enero 2022. URL: http://journals.openedition.org/artelogie/8122 ; DOI: https://doi.org/10.4000/ artelogie.8122

Este documento fue generado automáticamente el 7 enero 2022.

Association ESCAL 


\title{
La Siempre Viva Ciudad de México, antigua Tenochtitlán y futura Mexilópolis intergaláctica
}

\author{
Marisa Lara y Arturo Guerrero
}

1 Marisa Lara y Arturo Guerrero constituyen el equipo "Siameses Company", también conocidos como "Los Siameses Maritzin y Arturótl". Con más de cuarenta exposiciones duales, su obra forma parte de importantes colecciones de museos en el mundo: http:// www.siamesescompany.com/

2 La Siempre Viva Ciudad de México, antigua Tenochtitlán y futura Mexilópolis intergaláctica

3 Hemos escrito estas líneas a la par, entre dos que somos. Lo hicimos simultáneamente del mismo modo como acostumbramos hacer arte. Por eso, somos conocidos como freaks del arte contemporáneo justamente por nuestro cuerpo doble, producto de un experimento en el laboratorio de nuestra creación artística. Si bien nuestra fisonomía no es la común, tenemos la ventaja de que dos cerebros piensan más que uno y que pagamos pasaje dos por uno.

4 Nuestra ciudad, la de Los Siameses, es el lugar donde nacimos, por el que sentimos un enorme amor. México es una ciudad de contrastes que atrae y que repele, una ciudad amable y dura. 
1- "Alma de cocodrilo", óleo sobre lienzo, 2.15 x 1.95 cm, 1990

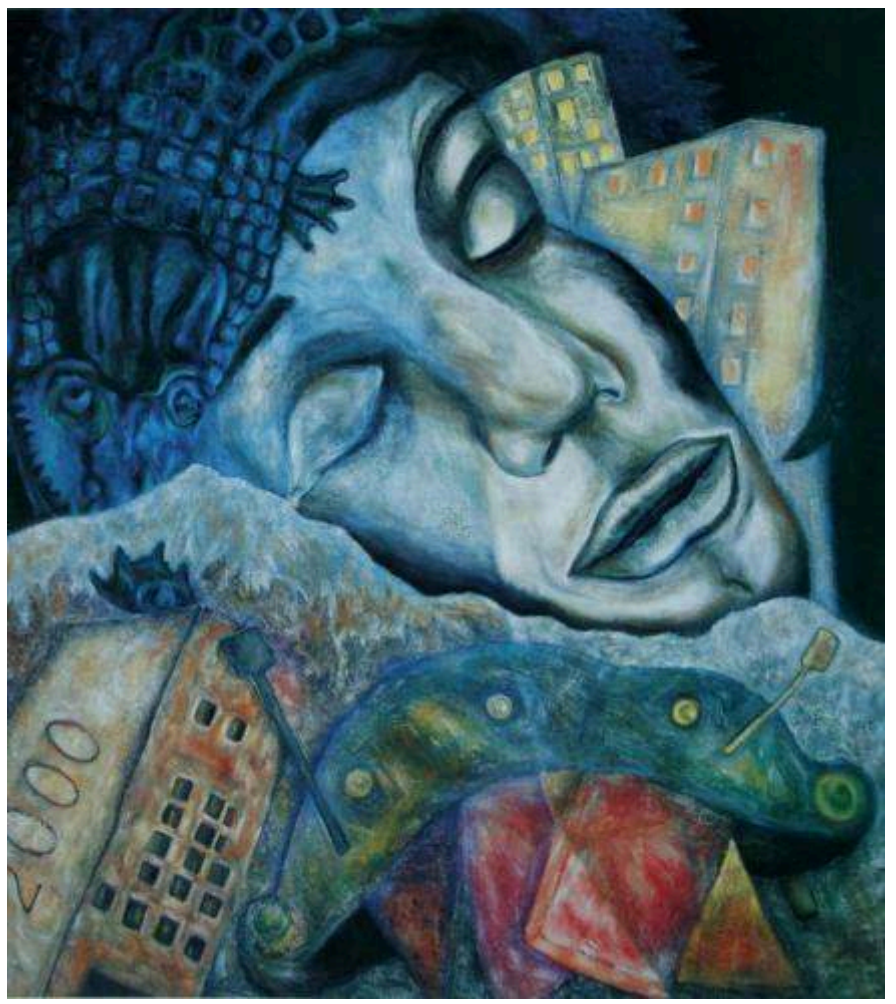

5 La relación que tenemos con la metrópoli en la que estudiamos, en la que como artistas nos formamos, en la que habita mucha de la gente que más queremos, la que nos cobija, nos impulsa y nos hace reconstruir la vida todos los días, es una relación contradictoria.

6 Llena de sueños y desengaños, de amistades y soledades, es un laberinto de emociones encontradas, una mezcla constante de modernidad y tradición. Durante los largos periodos que hemos vivido en el extranjero, la evocamos con melancolía y cuando pasamos demasiado tiempo en ella, nos sentimos fatigados por el extraordinario dinamismo que exige su enorme dimensión. La hemos recorrido de extremo a extremo, la conocemos desde su entraña, en su faceta popular, en su rostro chic, en sus tradiciones de barrio, en sus malls y centros comerciales de primer mundo, en sus tianguis y mercados. En selectivas reuniones realizadas en residencias indescriptiblemente ostentosas y en encuentros amistosos festejados en humildes viviendas. Hemos conversado con mexicanos que hacen sus negocios desde un lujoso barco en alta mar, desde el otro lado del mundo y que disfrutan los tacos con salsa picante que llevan en sus congeladores. También lo hemos hecho con mexicanos que en medio de mil carencias económicas gastan todo su raquítico patrimonio en una fiesta de quince años para su hija adolescente ofreciendo a los invitados los mejores tacos jamás probados.

$7 \mathrm{El}$ arte es un navío que nos ha llevado sin fronteras ni limitaciones por el mundo y nuestra Ciudad de México no es la excepción. Como Los Siameses que somos, nacimos con éste nuestro cuerpo doble en la década de los ochenta, hace veintiocho años, en el laboratorio de nuestra experimentación artística.

8 Nuestra condición de freaks se gestó en la metrópoli y en ella nacieron nuestro pensamiento y nuestro corazón. Las grandes ciudades son el escenario de nuestras inquietudes. La Ciudad de México es el torbellino en el que nacimos. Es el inmenso 
animal que despierta cada madrugada para enfrentar la realidad, luchar y resistirse a sucumbir. Su complejidad es la de un vasto abanico de encuentros y desencuentros entre lo rural y lo urbano, entre el pasado y el presente, entre las clases sociales, entre las edades de sus habitantes, entre el sueño y la realidad...

Crisis económicas, epidemias, terremotos, inundaciones y calamidades de toda índole la han azotado durante toda su vida y la gente ha salido a flote combatiendo con valentía. México es una ciudad de grandes eventos multitudinarios, desde grandes manifestaciones culturales y manifestaciones políticas, hasta gigantescos festivales de todo tipo.

La gente de la ciudad responde luchando, aunque los políticos y las autoridades no estén a la altura. Existen días en que amanece abatida de tanta realidad.... Su vida económica es de altos contrastes; junto a la pobreza de la mayoría se desarrolla una riqueza extrema destinada a unos cuantos. Por eso, la metrópolis es el reino de la economía subterránea, del comercio ambulante, de la piratería, del desempleo fincados en el mismo territorio urbano donde se hallan las cabezas de los consorcios más poderosos, la bolsa de valores, los grupos financieros, las organizaciones empresariales de mayores capitales y las colonias y corredores comerciales destinados a niveles adquisitivos clasificados entre los más pudientes del mundo, aunque sólo un puñado los disfrute.

11 Es el territorio de los vehículos automotores para los que vías modernísimas se construyen y que dejan en segundo plano la circulación de ciclistas y peatones.

\section{2 - "Lo cotidiano", óleo sobre lienzo, 1.40 x 1.55 cm., 2000}

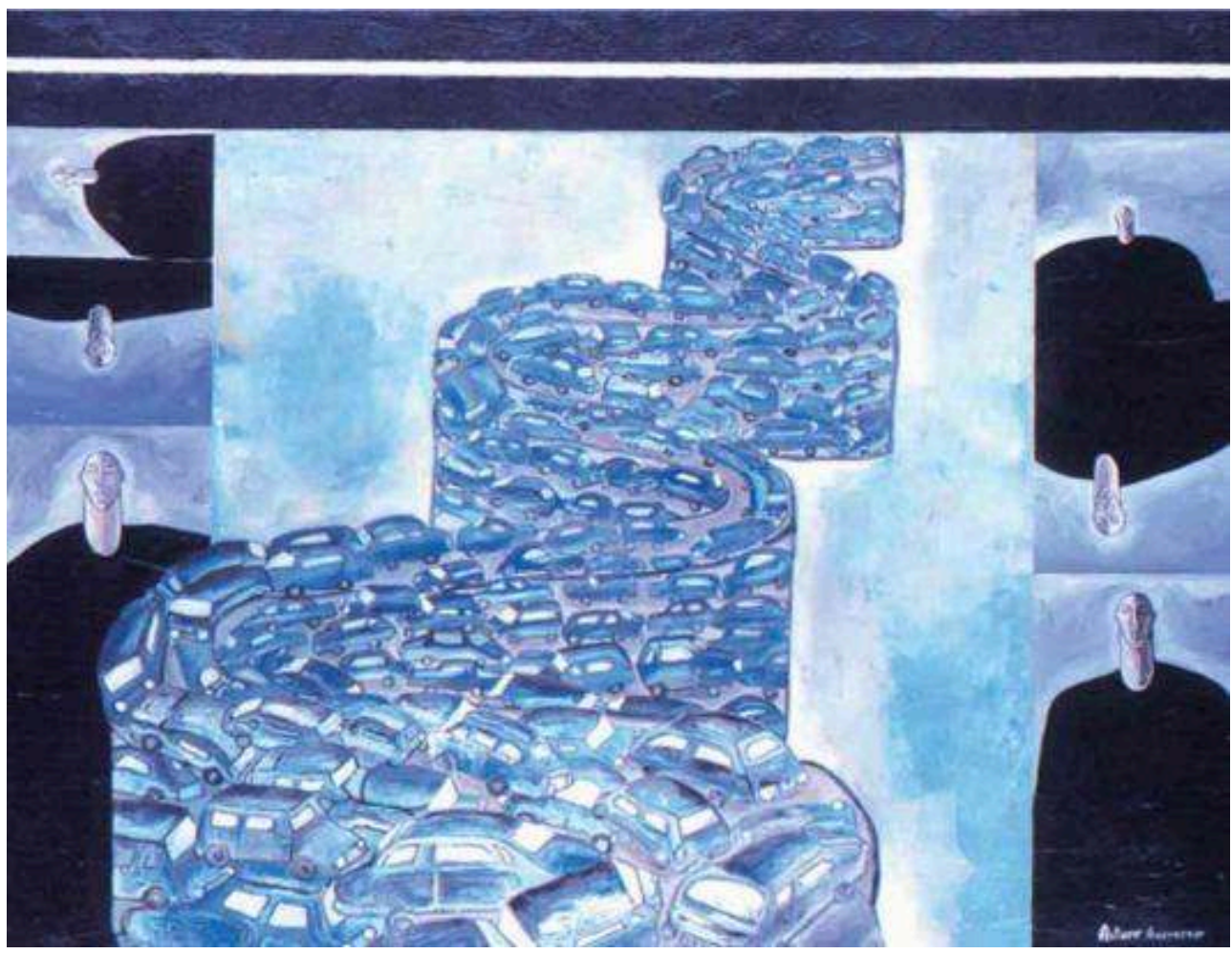

En sus zonas importantes económicamente, la Ciudad de México despliega hermosas avenidas arboladas, barrios residenciales con casetas de vigilancia, inaccesibles sin 
rigurosas identificaciones de por medio, servicios de élite en abundancia, zonas comerciales exclusivas y protección civil.

También es una ciudad de clase media alta bien vestida que vive en cómodos barrios y espacios muy agradables, usa autos de recientes modelos, tecnología de avanzada y contrata servidumbre para su vida cotidiana. Viven relativamente tranquilos rodeados de comodidades, viajan constantemente al extranjero y tienen lindas, espaciosas y jardinadas casas de campo en otras ciudades y lugares rurales alrededor de la capital.

3 - "La edificación de la luz", óleo sobre lienzo, 1.25 x 1.40 cm., 1990

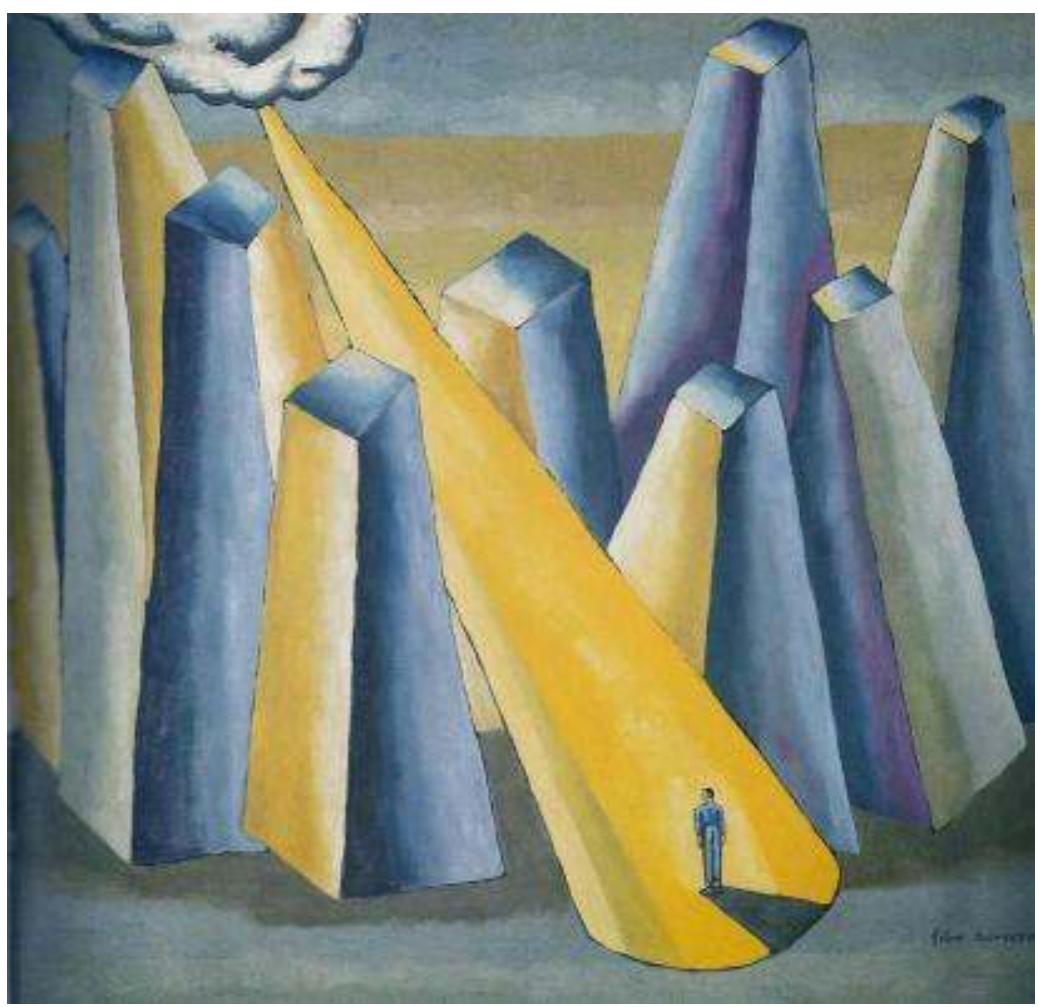

Una ciudad que con todo y el consumo de sus millones de habitantes - casi veinticinco incluyendo a la periferia - se mantiene ordenada y limpia, circulable. ¿No es acaso una proeza civilizatoria lograr la convivencia cotidiana de tal cantidad de gente que aborda el metro organizadamente, o de tal cantidad de autos que circulan sin atropellar en cada esquina a los peatones? ¿No es acaso una proeza atravesar la extensa geografía de asfalto para llegar al trabajo luego de una jornada de diez horas, más tres horas de traslado promedio, para ganar un sueldo que apenas alcanza para comer? La vida palpita en las entrañas del monstruo. La gente lucha por vivir mejor. Nuestra ciudad, la de Los Siameses, vive intensamente. 
4 - "Humo en los ojos", óleo sobre lienzo, 2.15 x 1.95 cm, 1990

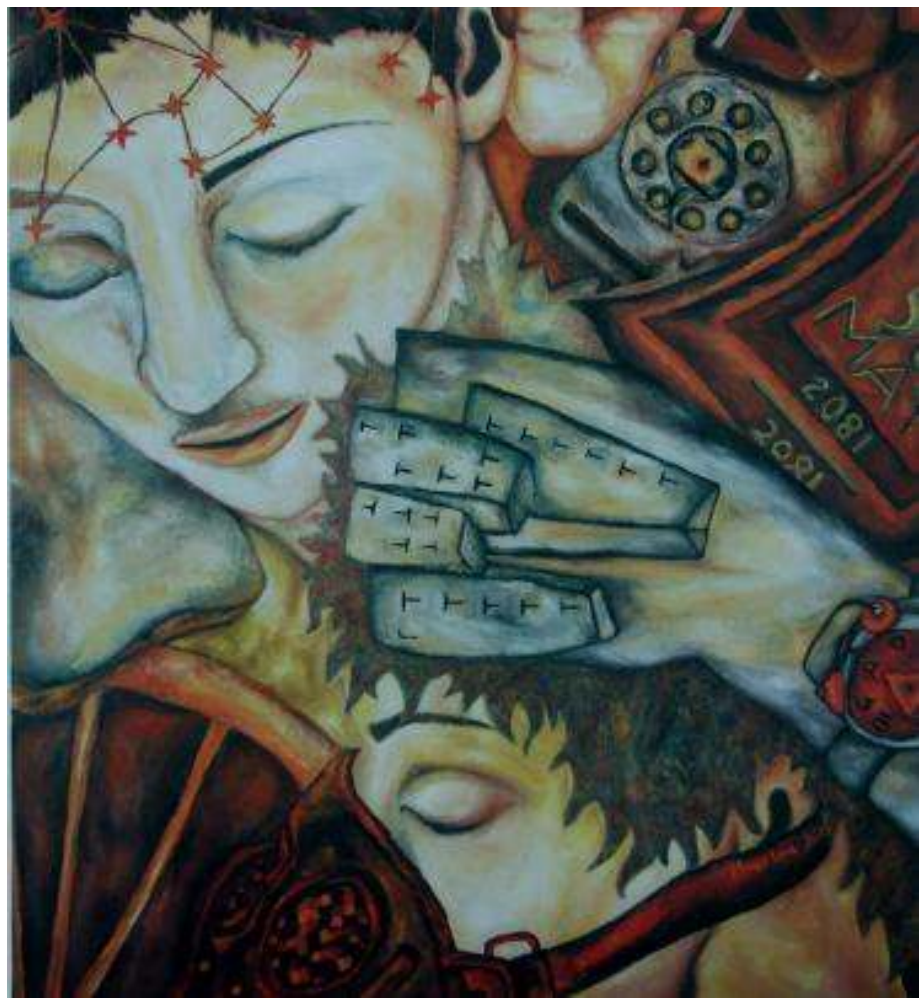

15 La lucha libre, tan popular y exitosa entre la población que emocionada asiste a las arenas para arengar a sus ídolos enmascarados, es una analogía de estas batallas cotidianas. Los enmascarados gladiadores representan a la población, son sus héroes, los ídolos del pueblo que Los Siameses hemos pintado en nuestros lienzos con devoción artística, cuando hace treinta años pocos intelectuales y artistas consideraban la cultura popular urbana un tema digno de ser tratado. 
5 - "El entierro de El Santo", òleo sobre lienzo, 1.75 x 1.50 m, 1984

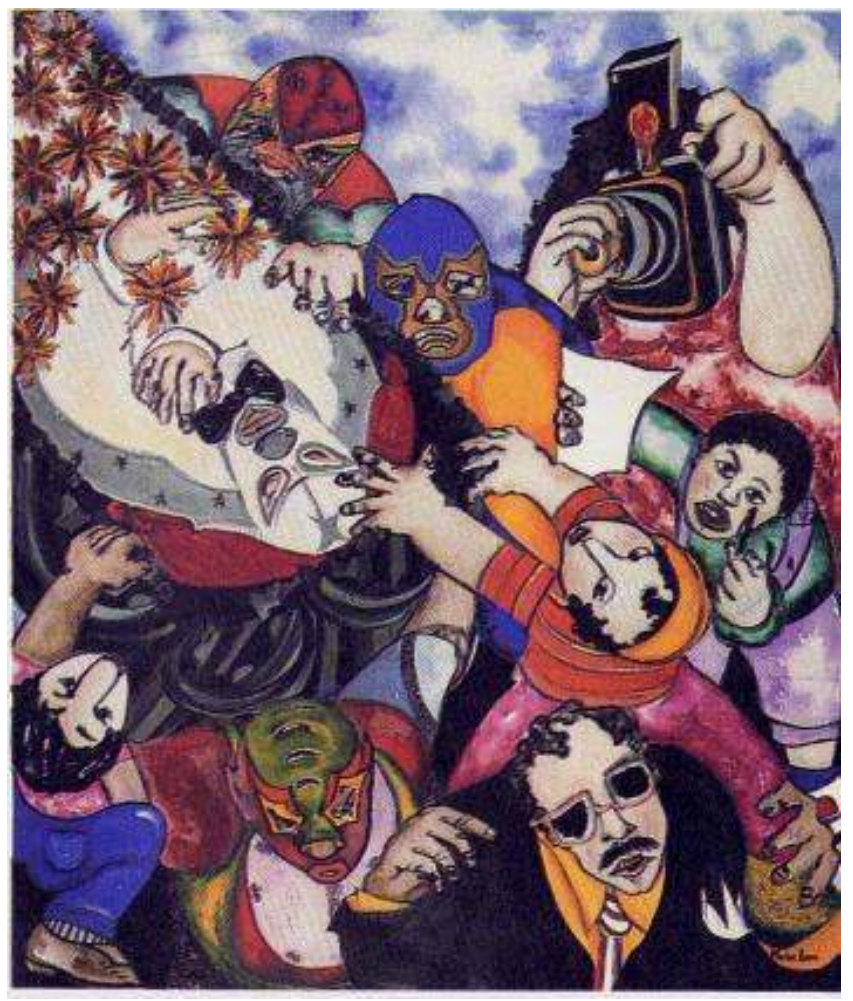

16 Lo mismo sucedía con otras manifestaciones como el baile de barrio o las figuras de íconos populares, cuando nosotros Los Siameses amorosamente les acogimos en nuestros temas artísticos, les dimos un lugar en nuestras expresiones de arte y los devolvimos a la cultura visual contemporánea con las luces que les agregamos. 
6 - "Todo se lo debo a la virgencita...", oleo sobre lienzo, 1.80 x 1.50 m, 1986

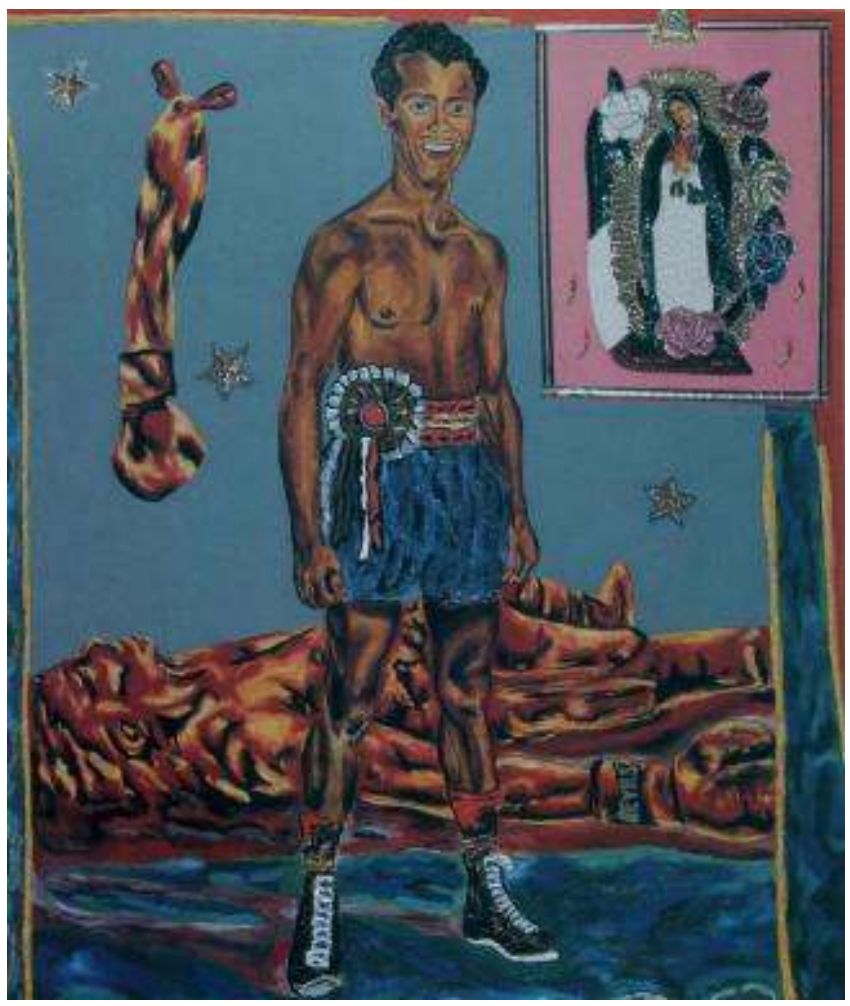

17 Así, las leyendas vivas de la cultura urbana y las del pasado se volvieron la sustancia de nuestra pasión de artistas. Amistades queridas y encuentros fraternales con personalidades como Paquita la del Barrio, Tongolele, Ninón Sevilla, Enrique Jorrín, Acerina, El Santo, Blue Demon, Celia Cruz, quienes son llamas intensas en la imaginación colectiva. Han habitado nuestras obras, pues los hemos hecho lienzos, esculturas e instalaciones.

Nuestros personajes también han sido aquellos que conforman el mismo cuerpo urbano: sus avenidas, calles, puentes, circuitos interiores, sus habitantes, sus autos, sus fiestas y bailes populares, los diversos rituales urbanos cargados de intensa vida emocional. Los Siameses dedicamos apologías hechas con sinceridad y afecto a figuras urbanas ya fallecidas, lejanas en tiempo a nuestra generación, como Pedro Infante, Jorge Negrete, Lucha Reyes, Tin Tan, a quienes nunca conocimos, pero que presentes en nuestra emoción forjaron con su presencia la historia moderna y contemporánea de la Ciudad de México y del país entero. 
7 - "Matador", òleo sobre lienzo, 1.80 x $1.50 \mathrm{~cm}, 1986$

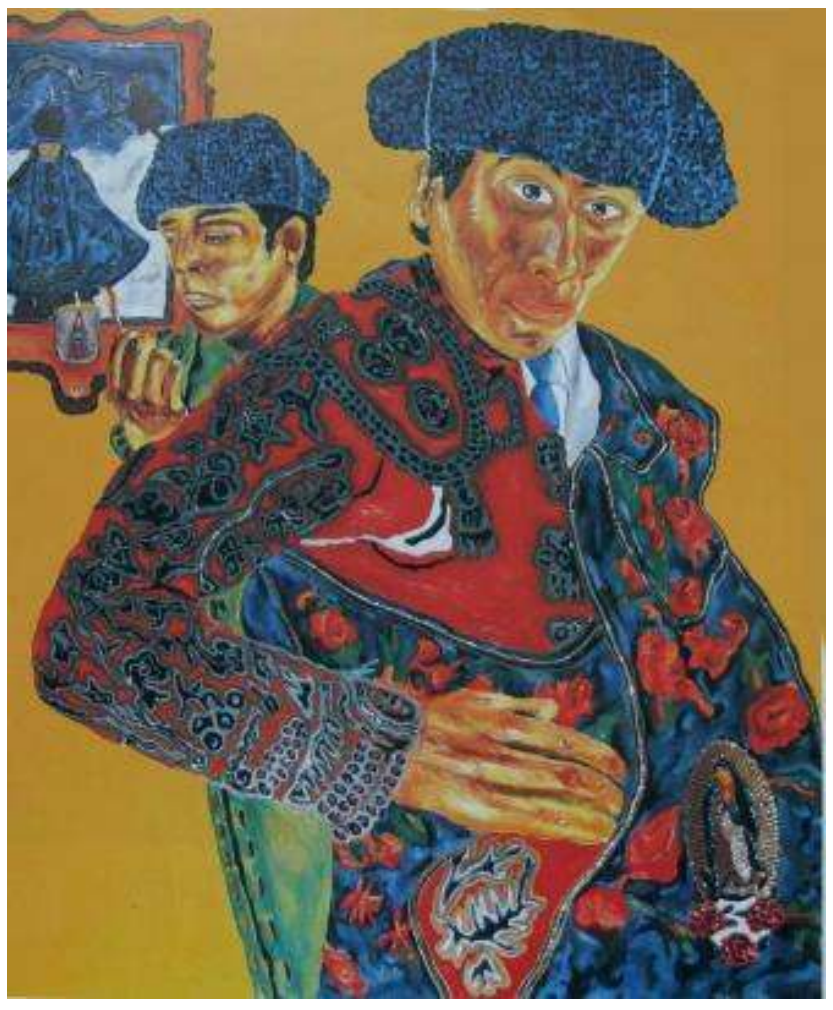

19 Lugar de amantes furtivos, donde la mayoría de los hoteles urbanos fuera de la clasificación cinco estrellas son usados para coitos apresurados, alquilados a colegas de oficina o a la gama polifacética de trabajadoras sexuales que ofertan sus caricias. 
8 - "La nave del cachondeo", òleo sobre lienzo, 1.40 x 1.25 cm, 1988

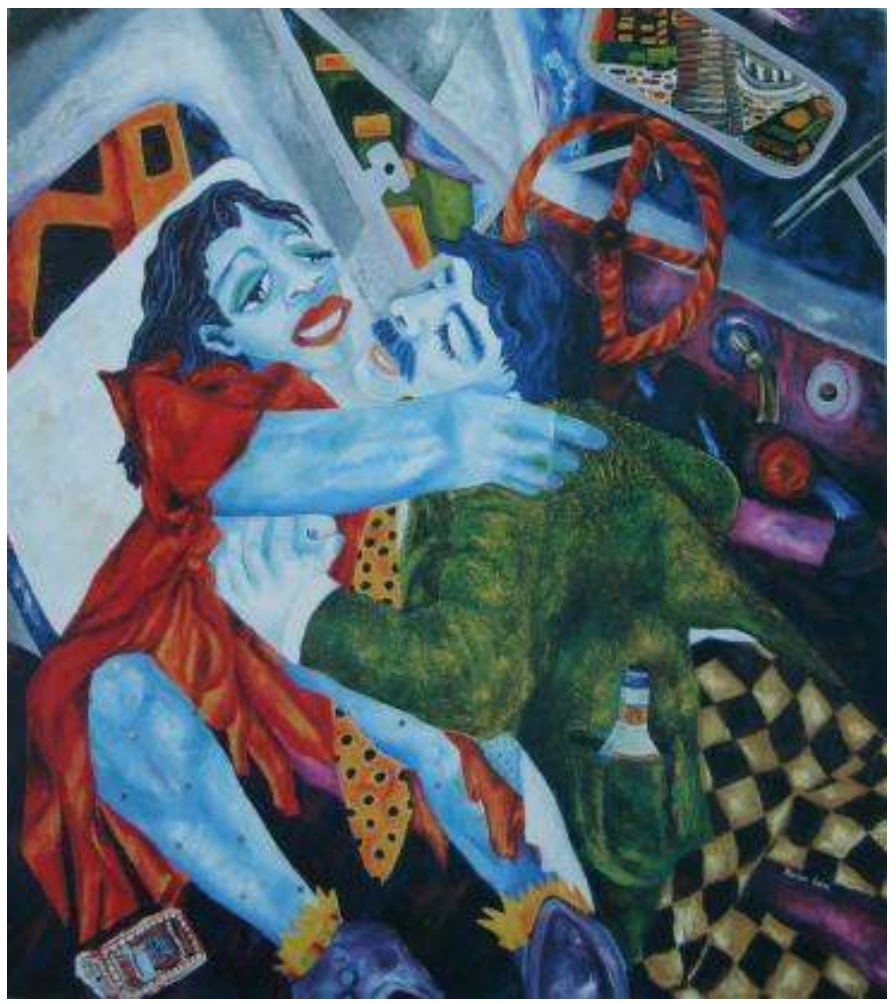

20 Nuestra ciudad, la magnífica Ciudad de México, el ombligo de la luna, la antigua Tenochtitlán, la descomunalmente grande metrópolis, la superpoblada de casi veinticinco millones de habitantes, es la "polucionada" capital de un país atravesado por la violencia delincuencial y la esperanza de la gran mayoría de los mexicanos, que a pesar de todo, salen a laborar construyendo día a día un porvenir creativo.

La ciudad situada en un valle cobijado por soberbios volcanes de nieve, en la que la gente trabaja duro jornadas extremadamente largas, que ríe pese a la desgracia y que hace esfuerzos por seguir siendo gentil en medio de las crisis económicas, los desatinos políticos y el desánimo social.

Estas líneas las escribimos Los Siameses como habitantes de una capital que se resiste al caos, a la inmovilidad, a la muerte. Un lugar en donde la gente lucha contra la adversidad, en el que las personas desean un futuro mejor, un espacio de ilusiones en el que todavia queremos creer que la mayoría no ha abandonado el humanismo ni el derecho a la felicidad. Nuestra capital ha protegido y dado alternativas de trabajo y de vida a muchos exiliados de guerra y de dictaduras, particularmente a españoles y a sudamericanos a lo largo de diferentes décadas. Tambien es una ciudad de migrantes provenientes de todo el mundo desde siglos atrás.

La solidaridad hacia los otros ha tenido gran importancia entre los mexicanos. También lo ha sido la respuesta de la sociedad civil ante los desastres como el terremoto de 1985 que dejó miles de muertos y edificios desplomados. La tierra se movió estrepitosamente y sus pobladores acudieron a rescatar a los heridos y a los muertos que se hallaban bajo los escombros. El país entero se conmovió profundamente ante la desgracia de los habitantes de la ciudad. 
9 - "Terremoto de amor", óleo sobre lienzo, 1.40 x 1.25 cm., 1988

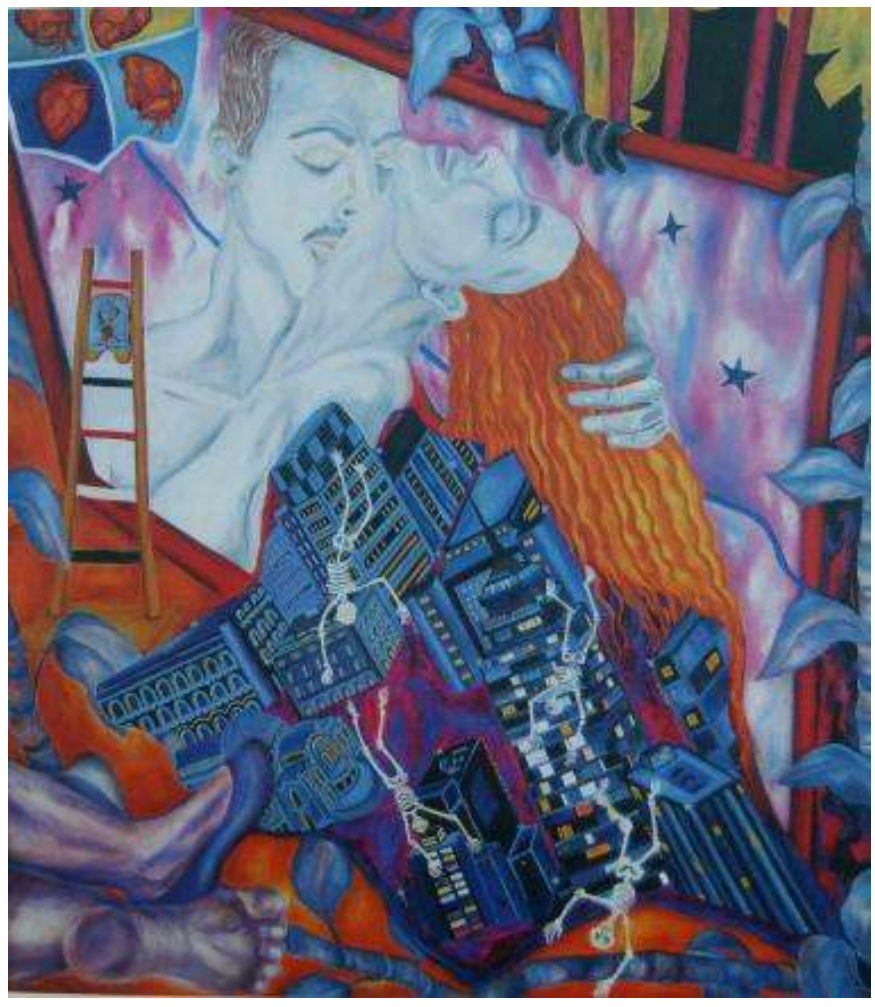

24 Siglos atrás, la ciudad fue de agua, construida sobre un lago inmenso en el que sus pobladores se desplazaban en pequeñas embarcaciones por sus calles y avenidas trazadas por canales fluviales, sobre los que se construyeron las casas, templos y palacios de los antiguos aztecas.

Cuando los españoles llegaron a la ciudad en 1519, no daban crédito a la belleza y a la modernidad de Tenochtitlán, la que impresionante por su organización y limpieza, equivalía a la Venecia italiana. Su templado clima la hace disfrutable durante cualquier época del año y casi diariamente sale un sol esplendoroso que seca generosamente la ropa de los tendederos instalados en las azoteas por toda la ciudad. 
10 - "La negra armadura de la profecía", óleo sobre lienzo, 1.95 x 2.25 cm., 1990

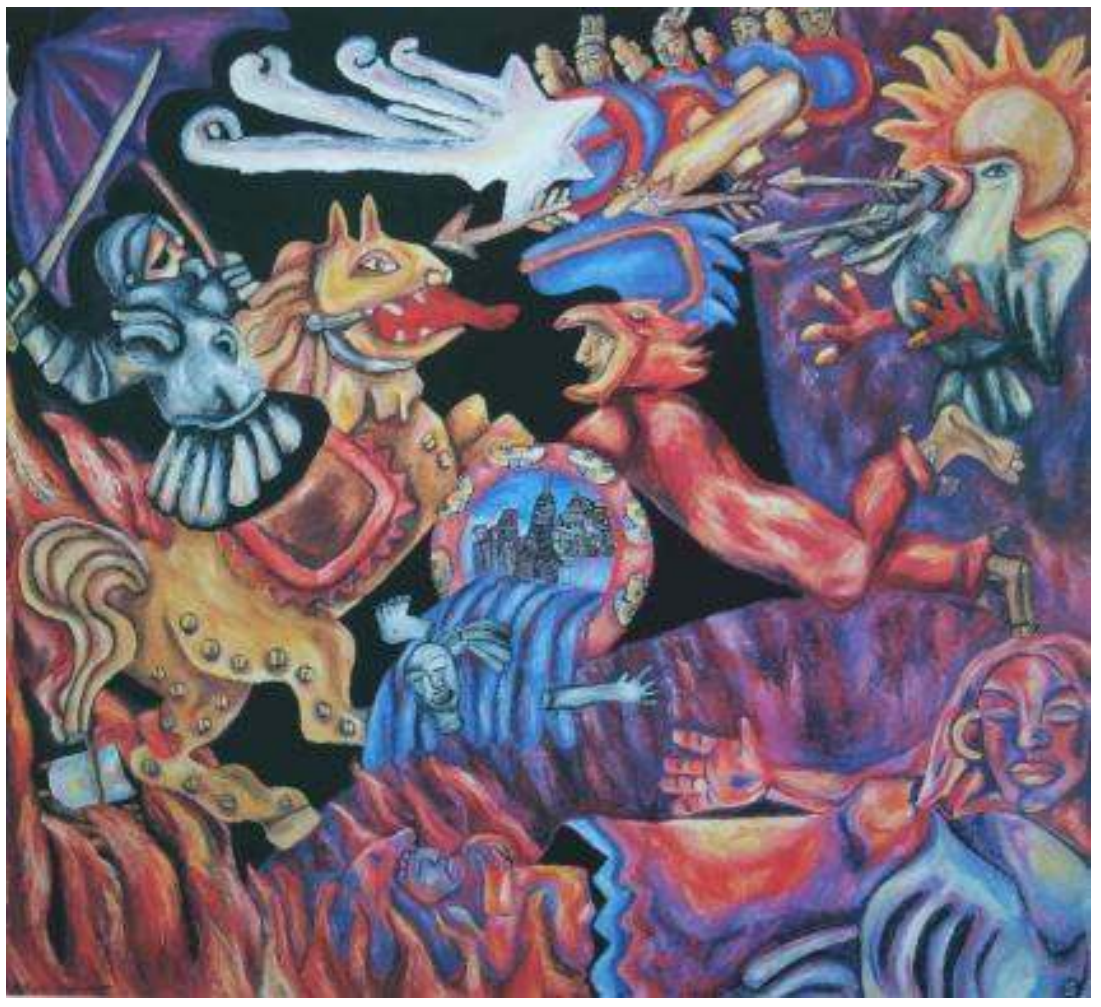

Hoy, al mundo llegan malas noticias de México, noticias de crímenes, de secuestros, de narcotráfico, de violencia. Pareciera que los ancestrales problemas de pobreza, los brutales contrastes sociales, el desempleo, la subalimentación, ya no son la principal nota de nuestro país. Las noticias alarmantes y espectaculares venden. Claro que existe la base para ello, pero se ignora que México es una ciudad donde se baila, donde la gente se reúne, los transeúntes se respetan, se hace investigación científica aún con recursos insuficientes, donde los niños saben leer y escribir, la gente viste a la moda y hasta sus científicos lograron inventar la píldora anticonceptiva y la televisión a colores. Es la ciudad que gestó en la segunda mitad del siglo XX tres Premios Nóbel.

Es la ciudad que el mundo ha volteado a ver cuándo sus artistas crearon el muralismo moderno y sus escritores pusieron a hervir la lengua española con una literatura que no se conocía. La de grandes fotógrafos, músicos universales e intelectuales relevantes. 
11 - "Ayúdeme Dra. Corazón", óleo sobre lienzo, 1.40 x 1.25 cm., 1988

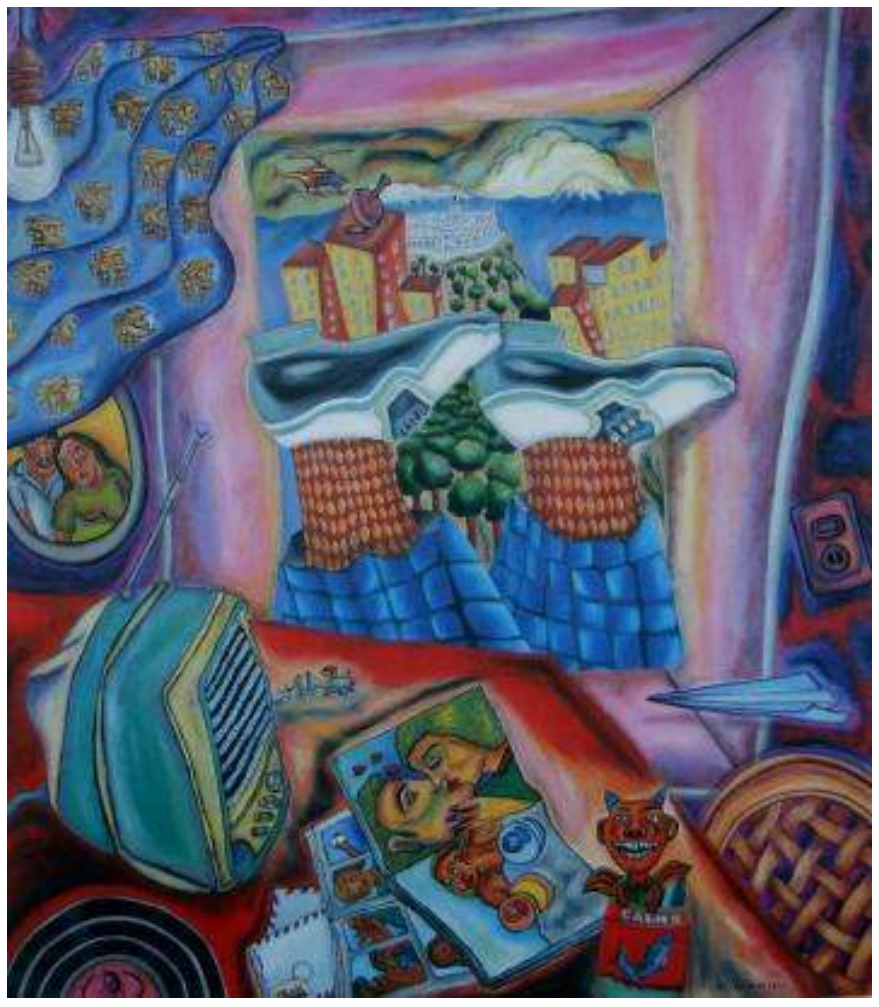

México es el país con una capital que representa el Nueva York de América Latina para los millones de pobladores situados del Río Bravo hasta la Patagonia. A ella llegan diariamente miles de mexicanos procedentes de todos los Estados de la República que se quedan a trabajar, a estudiar, a organizar sus vidas. Todos son acogidos: algunos con decencia y futuro, otros más con miseria y marginación. La ciudad es generosa, abraza y da cabida a millones de seres humanos, aunque también causa dolor a quienes la habitan. Todos la usan, obtienen beneficios de ella y pocos le devuelven respeto y mantenimiento. 
12 - "Motel La Conquista", óleo sobre lienzo, 2.25 x 1.95 cm., 1990

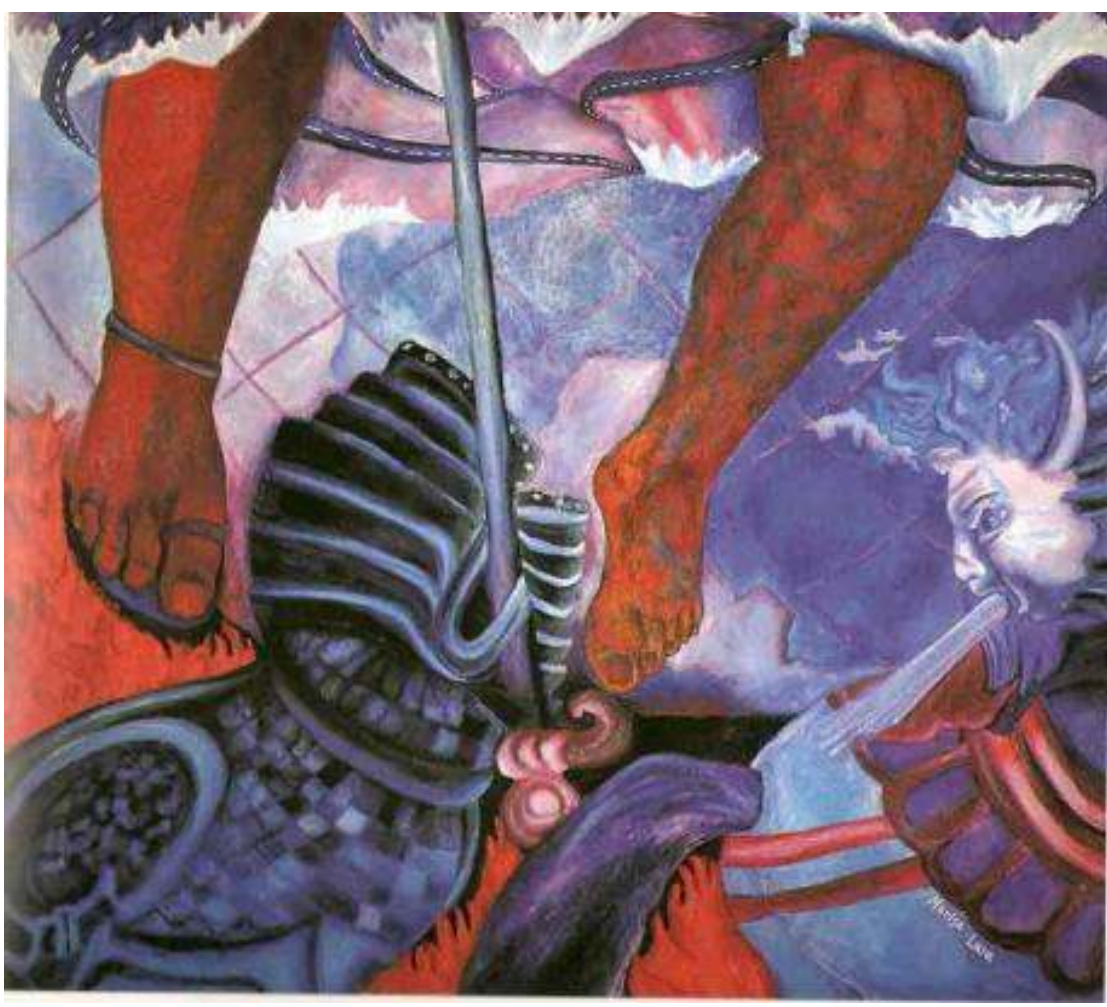

29 A pesar de la inmensidad de los problemas, la gente ama, se enamora, hace fiestas, consume desaforadamente, se moderniza, utiliza alta tecnología, vive y hace planes. Somos un pueblo que no se rinde aunque baile con la muerte. Y esto no dicho metafóricamente, en alusión a la tradición del Día de Muertos, sino porque la muerte acecha impunemente en manos del crimen organizado, hoy cáncer en la sociedad mexicana.

Mexico City ofrece a quien la visita un inconmensurable abanico de sitios de interés asi como una cantidad enorme de museos de todo tipo, espacios de arte, paseos, festivales, encuentros, espectáculos, vida cultural de primerísimo nivel en la que se presenta lo mejor de la República y del mundo entero. Así es nuestra ciudad, el lugar en donde viven artistas de talento en todas las disciplinas, espacio de tradición y modernidad conviviendo simultáneamente. 
13 - "Prestidigitación urbana", óleo sobre lienzo, 2.15 x 1.95 cm, 1990

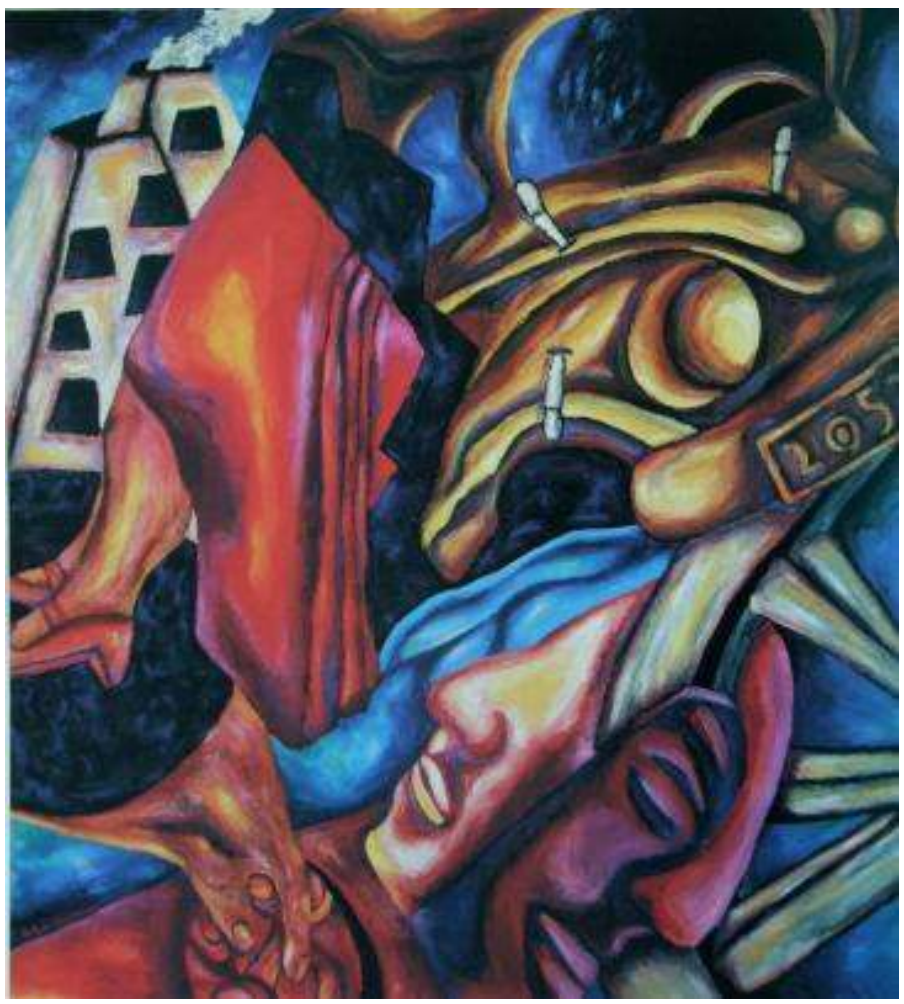

31 Nos-otros, Los Siameses, somos chilangos - así nos dicen a quienes nacimos en la capital. Quizá el nombre sea una derivación de la palabra chile, por cierto acompañante sagrado de la comida nacional. Nos piden que escribamos de nuestra ciudad. Es un tópico entrañable para nosotros pues hemos dedicado casi treinta años de nuestro trabajo al tema urbano y cientos de obras visuales de nuestra producción artística a la ciudad en la que nos desarrollamos y que en un momento nos lanzó al mundo y ha sido nuestra plataforma para la internacionalización. El dilema conservador entre lo particular y lo universal no lo es para nosotros, pues nos consideramos ciudadanos del mundo. La Ciudad de México se volvió global y este proceso se acelera cada día. 
14 - "El galope de Pegaso", óleo sobre lienzo, 1.25 x 1.40 cm, 1989

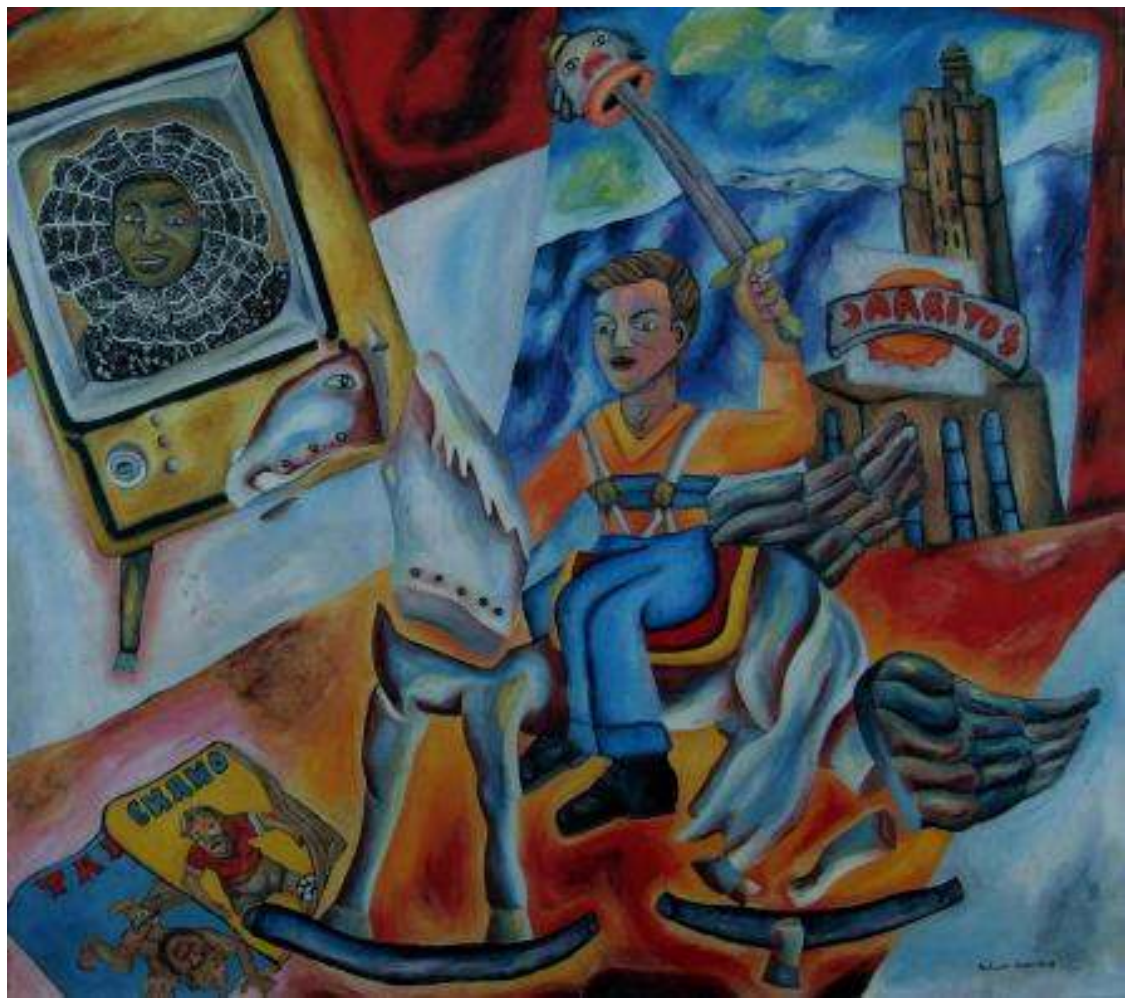

32 Crisol de culturas nacionales y extranjeras. Ciudad que contiene muchas ciudades en las entrañas. Nido de tráfago urbano. De vagones del metro atestados de pasajeros de toda índole que salen a trabajar cada mañana limpios, olorosos a jabón, bien peinados y con el cabello mojado. Rostros indígenas, mestizos, criollos, europeos. Cabezas azabache, rubias, pintadas, lacias o rizadas. Manos rudas de trabajadores, manos de uñas pintadas y decoradas, manos suaves de empleados de oficina y manos enrojecidas de trabajar en la limpieza. 
15 - "Humo en los ojos", óleo sobre lienzo, 2.15 x 1.95 cm, 1990

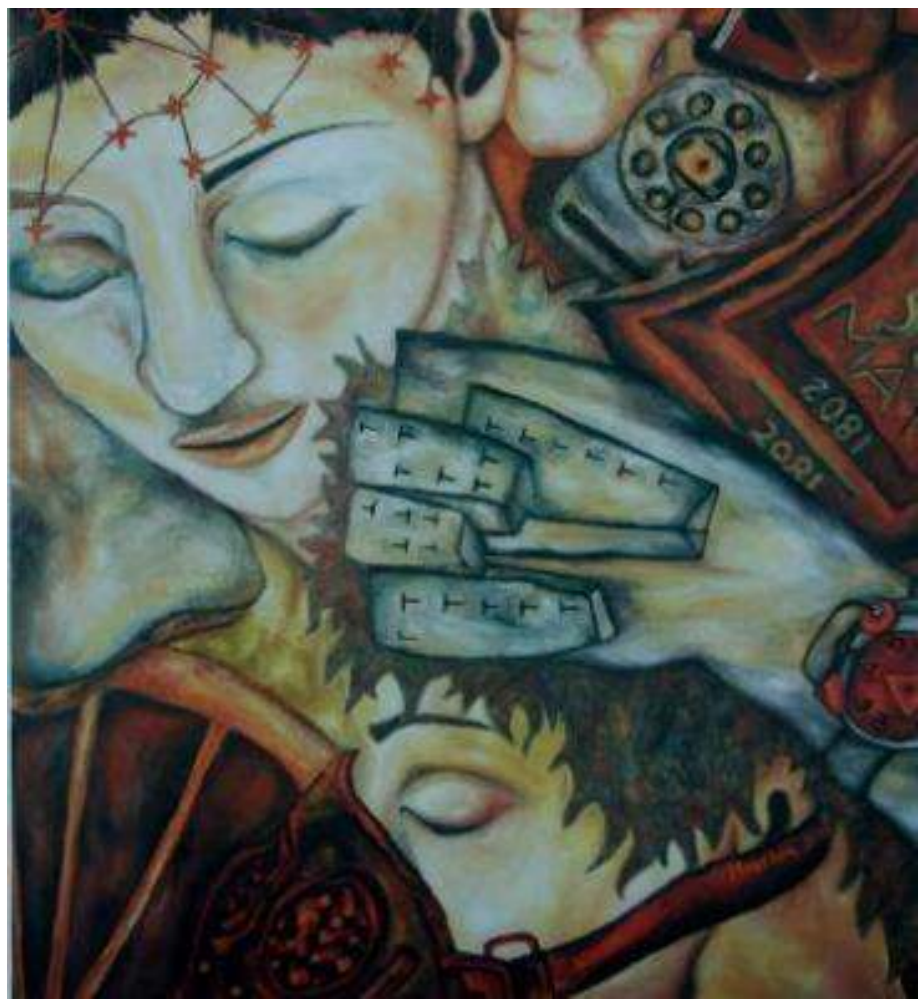

Ciudad de cuerpos mestizos. De jóvenes cada generación más altos y fornidos, vestidos como cualquier joven de Nueva York. Megalópolis de enormes edificios e ingeniería urbana con puentes fabulosos de varios niveles que se extienden por kilómetros y kilómetros de longitud y hacen de la capital un espacio futurista: Mexilópolis intergaláctica en cuyas venas y arterias circulan diariamente casi cinco millones de autos. En la capital de México se dan cita diversas lenguas indígenas, un español barriobajero de caló, un correcto español bien hablado y perfectamente pronunciado, entre la población citadina que cada día habla más inglés y entiende de computación e Internet.

34 México es la también la capital de la última moda de firmas originales y piratas. La República china dentro de la República mexicana. México en la moda del mundo, el mundo en la moda mexicana.... Hay comida de todo: lujosos restaurantes de comida internacional y una gastronomía nacional exultante. Pequeños y populares negocios de comida corrida - el arroz ¿con plátano o con huevo?, preguntarán las meseras. Fondas pozoleras con sopes y gorditas de chicharrón. Tacos, tortas, tamales de la patria del maíz acompañados de magistrales salsas picantes que crean adicción. Mercados con frutas coloridas que en Europa no se prueban: tunas, pitayas, zapotes, mameyes, guanábanas...Plátanos machos que se dicen ¡originarios de México..!

Correosa, la ciudad resiste golpes letales. Selva de asfalto, jungla de cemento, de abundantes taxis conducidos por choferes agobiados. El viaje incluye noticiero radial, jerga en el respaldo, desodorante barato y vueltas prohibidas. Los desgastantes trayectos de tráfico desbordado y hacinamiento automotriz son gratis. 
16 - "La linterna indiscreta", óleo sobre lienzo, 1.10 x 1.30 cm, 1988

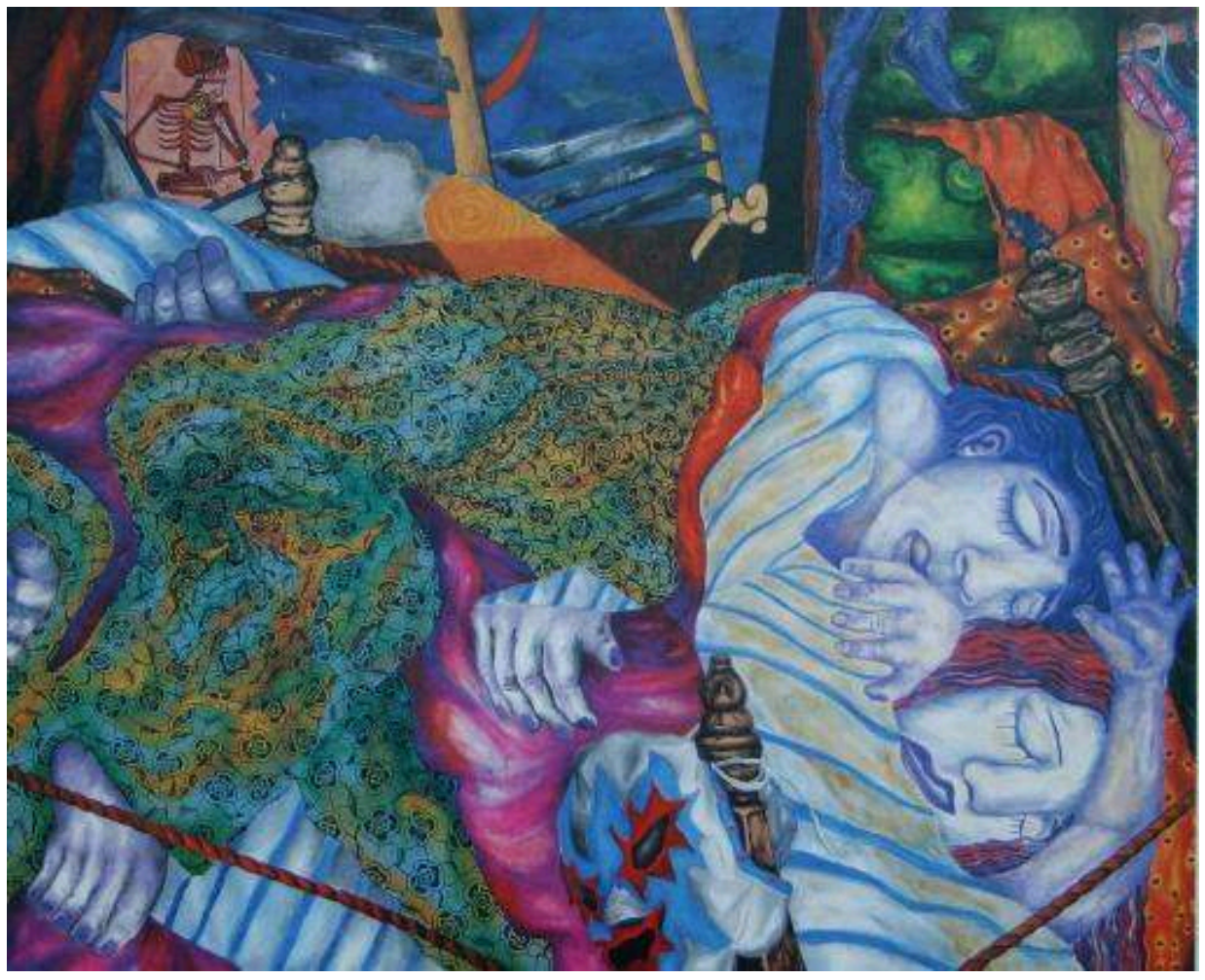

Ciudad de tristes perros callejeros que saben atravesar las avenidas cuando la luz verde de los semáforos lo indica.

Un ejército de desempleados, feligreses de la resistencia psicológica para seguir viviendo, se gana el pan atacando parabrisas de los coches con un trapo desgastado y un bote con sucia agua jabonosa. Mamás vendiendo papas fritas con el niño a cuestas y una especie de mecánicos espaciales con uniforme que vende tarjetas telefónicas. El agua embotellada se vende hoy al por mayor. Mañana será el aire embotellado.

El arte brota por todas partes. Parece una rebelión contra el destino gris y rutinario. Escultores callejeros de alambre de cobre, autores de figuras fantásticas, bailarines improvisados en los altos, actores mimos mal maquillados y apresurados que ofrecen el circo en el instante que dura un semáforo, poetas en los vagones del metro. Artistas con talento, desperdiciados, olvidados.

Y al mismo tiempo, en los barrios privilegiados, lujosas galerías en las que igual se muestra un arte barato en su expresión, pero de precios elevados, arte de franquicia, arte de ociosidad, que lo mismo se encuentran propuestas innovadoras, frescas y significativas. 
17 - "Las puertas del infierno", óleo sobre lienzo, 2.42 × 3.07 cm, 1994

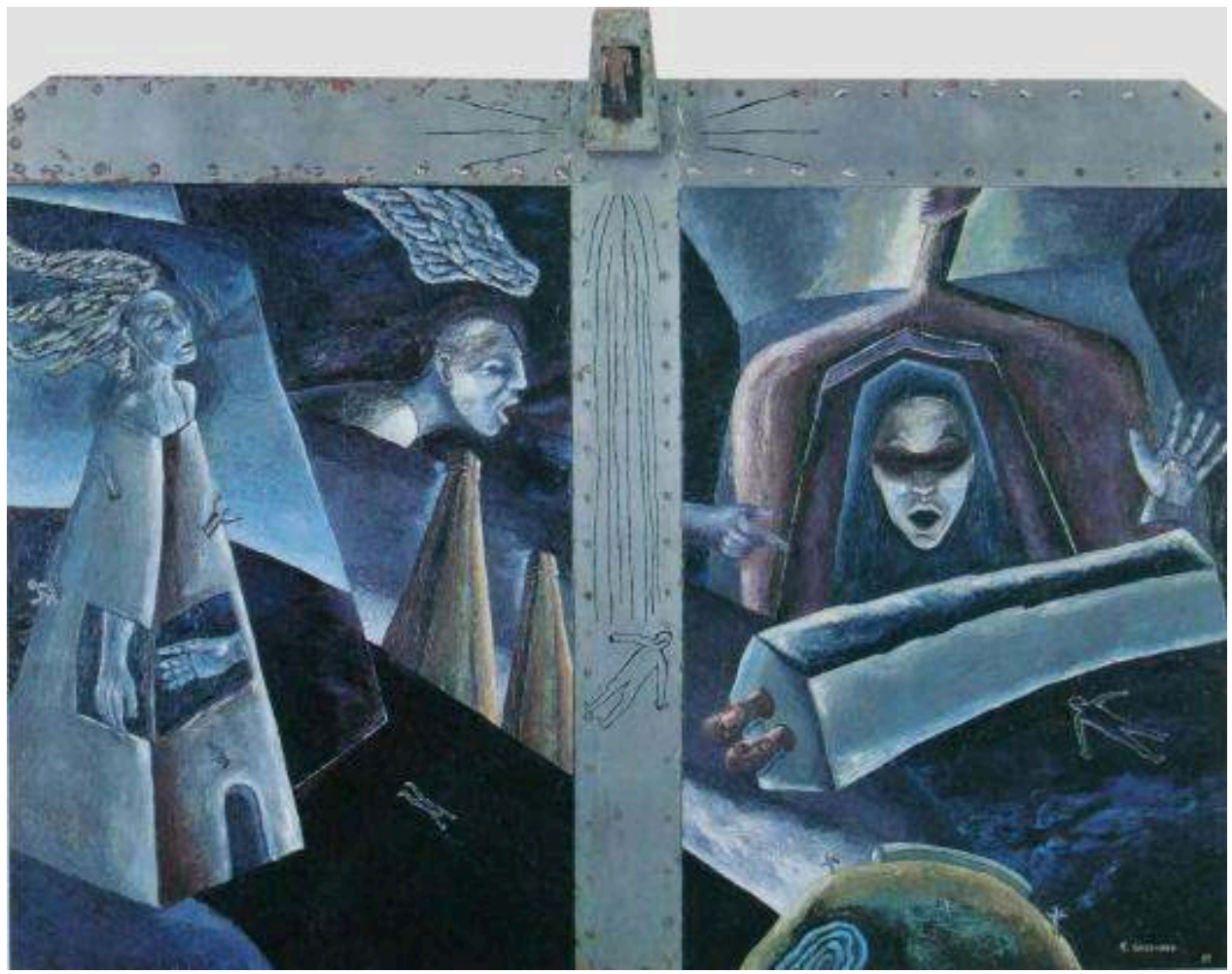

Los verdaderos embajadores de México en el mundo somos los artistas y los artesanos. Llevamos lo mejor de las expresiones artísticas a otras latitudes. El país se conoce a través de los ojos de sus artistas, de sus músicos y sus bailarines, de sus escritores, de su cine, de su fotografía, de su gastronomía. No son los políticos o los funcionarios quienes lo prestigian en el orbe.

41 A pesar del complejo fenómeno de la globalización, del que ninguna cultura, ninguna ciudad del planeta se sustrae, del que ninguna expresión artística contemporánea está alejada, sería demasiado simplista difundir y concluir que el alma del planeta, formada por sus diversas culturas y expresiones de arte, constituye una simple y vulgar cadena de franquicias, una suma de repeticiones maquilladas de un mismo rostro tedioso, aburrido y sin imaginación.

42 Aunque de esto quieran convencernos el cretinismo, la ignorancia y el dogmatismo de los mercados de poder basados en el discurso del dinero. Es verdad que existe el árido planeta de la infertilidad creativa y lo hace cuando la propia vida y no sólo el arte, son tazados en cifras monetarias y en sus desiertos solo florece la avaricia.

43 Este oscuro lado del mundo pervive junto al opuesto al que no logra derrotar, que es el mundo de las ideas, de la inteligencia, de las pasiones, de las convicciones, de la diversidad y el respeto por la otredad.

Coyoacán, septiembre de 2011. 


\section{RESÚMENES}

Se trata de un texto realizado conjuntamente par Marisa Lara y Arturo Guerrero, artistas visuales nacidos en la Ciudad de México, que integran el equipo "Siameses Company". Constituye una reflexión sensorial de la Ciudad de México a través de sus costumbres, sus contradicciones y sus claroscuros. Cuenta las complejas relaciones entre tradición y modernidad; ubica a la megalópolis en el panorama de la globallización internacional; menciona relaciones entre la considerada alta cultura y la cultura popular y expresa elementos idiosincráticos que son latentes en la sociedad mexicana contemporánea. Los autores conocen su ciudad, la viven intensamente y la han hecho tema de sus pinturas, esculturas, grabados, fotografías, instalaciones y performances a lo largo de veintiocho años de trabajo artístico profesional caracterizado por la creación al alimón, de manera conjunta.

\section{ÍNDICE}

Palabras claves: arte mexicano, cultura contemporánea mexicana, tradición, modernidad, identidad cultural, Ciudad de México, globalización mexicana, siameses compagny, freaks del arte contemporáneo, pareja de artistas mexicanos, galerias y museos de México

\section{AUTORES}

\section{MARISA LARA}

Siameses Company - Artista multimedia, México D.F.

\section{ARTURO GUERRERO}

Siameses Company - Artista multimedia, México D.F. 